\title{
Invasion of Ureaplasma diversum in bovine spermatozoids
}

\author{
Melissa Buzinhani, Maurício Yamaguti, Rosângela C Oliveira, Beatriz A Cortez, Lucas Miranda Marques, \\ Gláucia M Machado-Santelli, Mayra EO Assumpção and Jorge Timenetsky*
}

\begin{abstract}
Background: Ureaplasma diversum has been associated with infertility in cows. In bulls, this mollicute colonizes the prepuce and distal portion of the urethra and may infect sperm cells. The aim of this study is to analyze in vitro interaction of $U$. diversum isolates and ATCC strains with bovine spermatozoids. The interactions were observed by confocal microscopy and the gentamycin internalization assay.
\end{abstract}

Findings: $U$. diversum were able to adhere to and invade spermatozoids after $30 \mathrm{~min}$ of infection. The gentamicin resistance assay confirmed the intracellularity and survival of $U$. diversum in bovine spermatozoids.

Conclusions: The intracellular nature of bovine ureaplasma identifies a new difficulty to control the reproductive of these animals.

Keywords: Ureaplasma diversum, bovine spermatozoid, invasion, confocal microscopy

\section{Background}

Ureaplasma diversum and some mycoplasma species may cause reproductive failures in animals, but the pathogenicity of these mollicutes in such disturbances remains unclear [1]. U. diversum has been associated with infertility in cows and may result in severe placentitis, fetal alveolitis, abortion or birth of weak calves [2,3]. This ureaplasma can be released through milk, conjunctiva and vaginal secretions and colonize the prepuce of bulls allowing contamination of semen collected from artificial vaginas or be transmitted at sexual intercourse $[3,4]$. In addition, the distal urethra of bulls is highly colonized with microbes, and decontamination procedures do not sufficiently reduce the number of microorganisms in sperm, including the mollicute species [5].

Antibiotics may be added to semen before freezing in straws to prevent or reduce microbial contamination [6], yet the efficacy of this procedure has not been documented.

Mollicutes were initially considered surface parasites on the epithelial linings, but since 1992 in human origin mycoplasma, these bacteria have been detected inside phagocytic and non phagocytic cells [7]. Baseman et al.

\footnotetext{
*Correspondence: joti@usp.br

Departamento de Microbiologia, Instituto de Ciências Biomédicas,

Universidade de São Paulo, São Paulo, Brasil
}

[8] demonstrated an intracellular localization of mycoplasmas of human origin in non phagocytic cell lines. $U$. urealyticum colonizes the human urethra and has been detected inside human spermatozoan cells [9]. The cell invasion of animal origin mycoplasmas has been recorded for some mollicutes [7-9], but this ability has not been observed for $U$. diversum in bovine spermatozoids. In this study, bovine sperm cells were infected in vitro with strains and field isolates of $U$. diversum and analyzed by confocal microscopy and gentamicin invasion assay.

\section{Results}

Analysis of labeling-U. diversum and motility/vigor of infected spermatozoids

The infective dose multiplicity of infection was $10^{4}$ to $10^{7} \mathrm{CCU} / \mathrm{mL}$ with $0.01-10 \mathrm{CCU} / \mathrm{mL}$ of ureaplasmas per spermatozoa. The viability of ureaplasmas was confirmed by production of typical ureaplasma colonies on agar plates. The average sperm motility before infection was $40 \% \pm 14.71$ and vigor 3.5 . The motility and vigor after $30 \mathrm{~min}, 3$ and $6 \mathrm{~h}$ of infection were $20 \% \pm 12.81$ and 3 ; $10 \% \pm 7.35$ and $2 ; 2.5 \% \pm 2.75$ and 1 , respectively. The motility/vigor decreased by the time of incubation of infected and non infected spermatozoa.
C Biomed Central

() 2010 Timenetsky et al; licensee BioMed Central Ltd. This is an open access article distributed under the terms of the Creative Commons Attribution License (http://creativecommons.org/licenses/by/2.0), which permits unrestricted use, distribution, and reproduction in any medium, provided the original work is properly cited. 
Microscopy of spermatozoids infected with $U$. diversum The $U$. diversum strains and isolates were detected on the surface and inside the spermatozoids after $30 \mathrm{~min}, 3$ and $6 \mathrm{~h}$ of infection. The ureaplasmal fluorescence (red, displayed in orange, by the overlapping of red ureaplasma and green spermatozoids actin fluorescences) was observed located on the head, middle or tail of spermatozoids, but a specific pattern of this interaction was not detected. Figure 1 also provides images obtained with the field isolates and ATCC strains of $U$. diversum. Uninfected spermatozoa showed no red fluorescence. The surface location and intracellularity of $U$. diversum (strain 49782) in spermatozoid are presented in Figure 2 by sequential sectioning of a series of focal planes. Figure 3 shows isolate 94 inside spermatozoa after $30 \mathrm{~min}(\mathrm{a}, \mathrm{b}, \mathrm{c})$ and $3 \mathrm{~h}(\mathrm{~d}, \mathrm{e}, \mathrm{f})$ of infection.

\section{Gentamicin invasion assay}

The inactivation of ureaplasma after gentamicin exposure was determined to range between 90.00 to $99.94 \%$ of the initial inoculums after 3 hours of infection (Table 1 ). Determination of ureaplasmal CCU/mL before and after antibiotic exposure is presented in Table 2. The obtained frequencies of CCU values ranged from 0.18 to $1.81 \%$ for studied isolates and ATCC strains from cows. The isolated TOURO1 recovered from bull sperm presented 10\% frequency of invasion. The averages of invasion obtained after gentamicin exposure were not equal to the significance level of 5\%. Strains 49782 and 49783 did not show differences in the average of invasion, but were lower compared with the field isolates. Strain 49782 from bull sperm presented an average significantly lower than isolate TOURO1. Average of invasion of isolate TOURO1 was significantly higher than the ATCC strains and isolates recovered from cows. The strain 49783 and the isolates from cows did not present significant differences in the average of invasion, except isolate A203. This isolate presented a higher average of invasion than others.

\section{Discussion}

Reproductive disturbances in cattle may cause high mortality and low birth rates due the failure of conception, embryonic death and abortion. The success of embryonic development is partially predetermined by genetic characteristics of male and female gametes. However, fertilization and embryogenesis failures are both documented to be of a seminal origin [10], due to infectious agents. Mollicutes have also been isolated in reproductive tracts of bulls and cows and their presence has been related to the infertility and impairment of embryonic development Although it is believed that these bacteria remain attached to the surface of epithelial cells, studies have reported Mycoplasma spp. surviving inside nonphagocitic cells [8].

Winner et al. [11] reported the ability of the widespread avian pathogen $M$. gallisepticum to invade human epithelial cells and chicken embryo fibroblasts by the gentamicin invasion assay and double immunofluorescence microscopy. These techniques are considered accurate in differentiation of intracellular and extracellular location of mycoplasmas in host cells [11]. However, there are no reports of experimental infection of bovine cells with $U$. diversum by these assays. Herein the labeling $U$. diversum with $\mathrm{DilC}_{18}$ fluorochrome and spermatozoa with FITC-phalloidin for confocal microscopy was useful to observe the interaction of this mollicute with bovine spermatozoan cells. The $\mathrm{DilC}_{18}$ did not cause background fluorescence in the membranes of spermatozoids and did not affect the viability of ureaplasmas as mentioned for M. hominis, a human origin mollicute [12].

The infections were performed here in proportions of 0.01:1 to $10: 1 \mathrm{CCU} / \mathrm{mL}$ of $U$. diversum per spermatozoid, allowing appropriate analysis. Different rates of invasion were obtained and the lower proportion of ureaplasma/spermatozoid resulted at a greater rate of invasion (10\%) with isolated TOURO1. Ueno et al. [13]
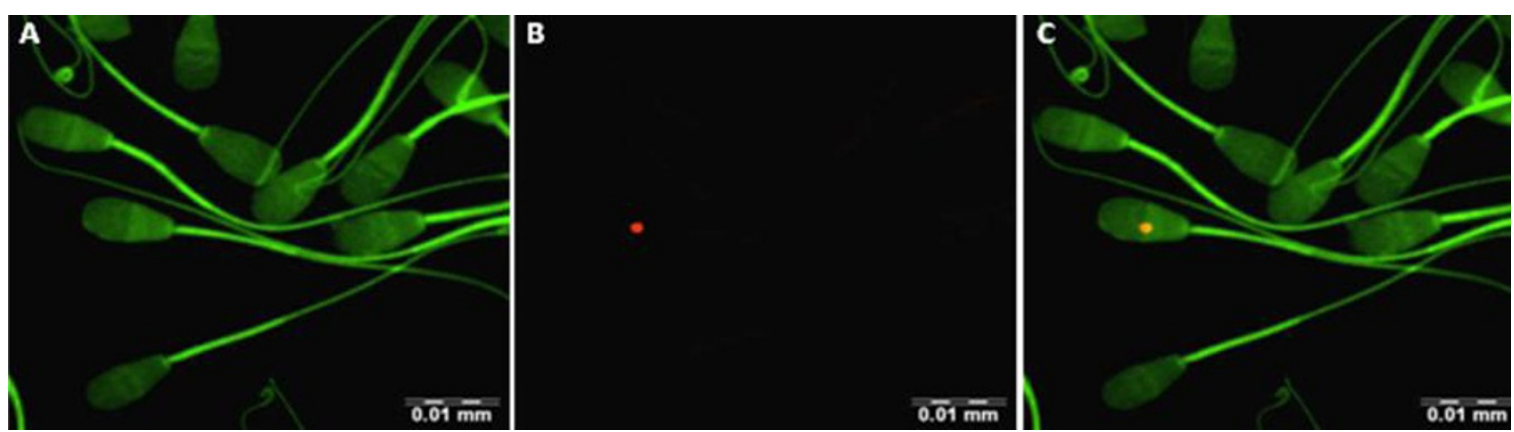

Figure 1 Interaction of DilC18-labelled $U$. diversum (isolate 94 after 30 min of infection) with FITC-labelled bovine spermatozoa in vitro. A: Spermatozoids in green fluorescence labeled with (FITC) B: Ureplasmas in red fluorescence labeled with (DilC) phospholipids. C: A composed of images $\mathrm{A}$ and $\mathrm{B}$. 

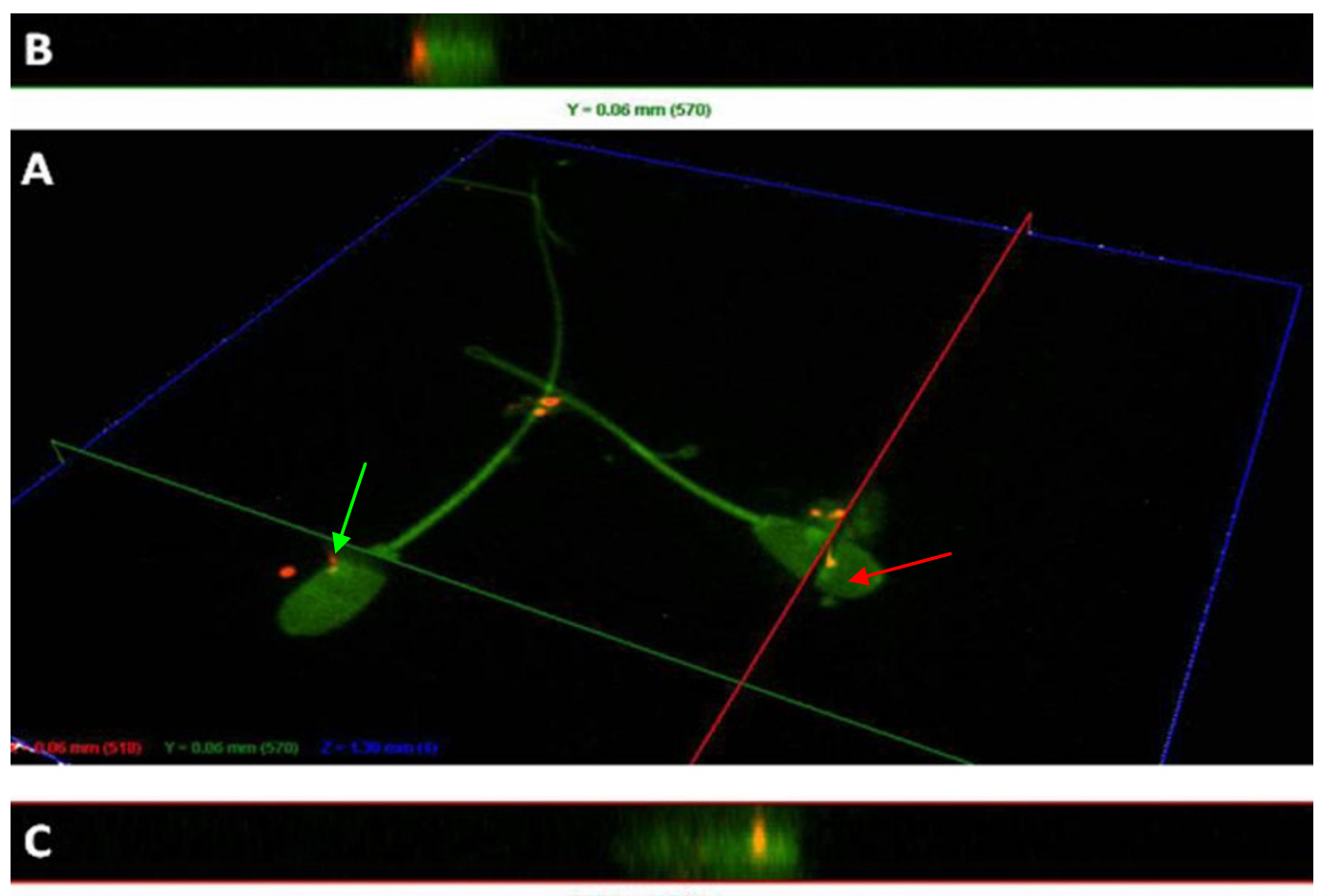

$x=0.06 \mathrm{~mm}(518)$

Figure 2 Interaction of DilC 18 -labelled $U$. diversum (ATCC 49782 after $3 \mathrm{~h}$ of infection) with FITC-labelled bovine spermatozoa in vitro. A: Orthogonal sectioning along the specified $x$-axis (red line) and $y$-axis (green line) with green arrows pointing to clusters of ureaplasmas attached to bovine spermatozoa and red arrows pointing to intracellular location. B: $y$-axis (green line) confirming the surface location of ureaplasmas (red fluorescent) in the spermatozoa. C: $x$-axis (red line) confirming the intercellularity of ureaplasma (red fluorescent) in the spermatozoa.

used the infective dose multiplicity of 1-7 M. genitalium per EM42 or HeLa cell and also obtained different rates of invasion.
The pool of semen from the three healthy bulls helped to standardize the study mainly for storage and the evaluation of motility and vigor of spermatozoids. The
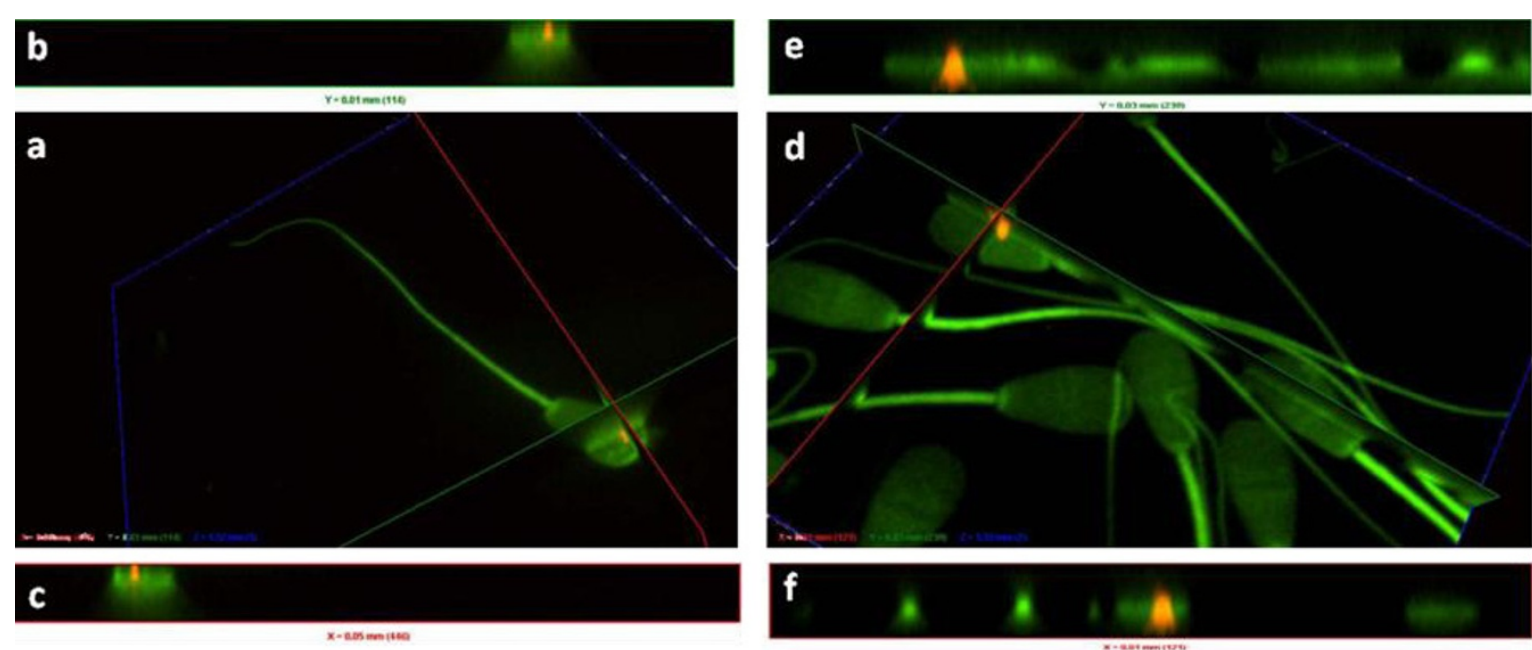

Figure 3 Interaction of DilC ${ }_{18}$-labelled $U$. diversum isolate 94 after $30 \mathrm{~min}$ (3a) and $3 \mathrm{~h} \mathrm{(3d)} \mathrm{of} \mathrm{infection} \mathrm{with} \mathrm{FITC-labelled} \mathrm{bovine}$ spermatozoa in vitro. $a / d$ : Orthogonal sectioning along the specified $x$-axis (red line) and $y$-axis (green line). b/e: $y$-axis (green line) confirming the internal location of ureaplasmas (red fluorescent) in the spermatozoa after $30 \mathrm{~min}$ and $3 \mathrm{~h}$ of infection. c/f: $\mathrm{x}$-axis (red line) confirming the internal location of ureaplasmas (red fluorescent) in the spermatozoa after $30 \mathrm{~min}$ and $3 \mathrm{~h}$ of infection. 


\begin{tabular}{cll}
\hline Strains and isolated of $\boldsymbol{U}$. diversum & \multicolumn{2}{c}{ Ureaplasmas inactivated by gentamicin } \\
\cline { 2 - 3 } & $\mathbf{C C U / \mathbf { m L } ^ { \boldsymbol { a } }}$ & $\%$ \\
\hline ATCC 49782 & 544500 & 99.00 \\
ATCC 49783 & 5490000 & 99.81 \\
A203 & 54000 & 98.18 \\
ALVA & 990000 & 99.00 \\
94 & 5490000 & 99.81 \\
3175 & 1000 & 99.94 \\
TOURO 1 & 9000 & 90.00 \\
\hline
\end{tabular}

${ }^{a}$ Values $\mathrm{CCU} / \mathrm{mL}$ of difference between initial inoculums and recovered after treatment with gentamicin, of 3 independent tests performed in triplicate and standard deviations.

methodologies used are in accordance with Zuccari et al. [14] who concluded that the passage through a column of Percoll $^{\circledR}$ is effective for selecting a higher population of motile spermatozoids with intact plasmatic and acrosomal membranes.

In present study, the motility and vigor of bovine spermatozoids infected with ureaplamas did not show significant difference compared to non infected spermatozoids, in the different time-intervals of incubation. This shows that in monitoring routine procedures, the infected spermatozoids are not distinguished when selected for fertilization. Previous studies reported that human spermatozoids infected with ureaplasmas presented high motility as in uninfected cells $[15,16]$. Núñes-Calonge et al. [17] reported that $2 \mathrm{~h}$ of contact with ureaplasmas presented as high a motility, but after $4 \mathrm{~h}$ of contact the motility decreased compared to non infected. The infected motile spermatozoa may access and fertilize the oocytes by fertilization in vivo or be selected for artificial insemination [9], however, may damaged paternal DNA and impair the embryonic development [16].

The use of fluorochromes to label ureaplasma and spermatozoids allowed distinguishing these cells when coinfected and observed through confocal microscopy in contrast as described in human spermatozoa infected with mycoplamas [12,17]. Knox et al. [9] used indirect immunofluorescent methodology and showed the adherence of $U$. urealyticum and $U$. parvum on the acrosomal region, midpiece and tail of human spermatozoids. Sylla et al. [18] otherwise related a specific pattern of interaction for $M$. mycoides ssp. mycoides LC in the acrosomal region and tail of bovine spermatozoa. Reichart et al. [16] used electronic microscopy and detected $U$. urealyticum within the cytoplasmatic space in human and ram spermatic cells. The ability of $U$. diversum to invade bovine spermatozoids points to a new feature for better controlling the reproductive failures of these animals.

The differentiation between extracellular and intracellular ureaplasmas was performed by planes $\mathrm{Z}$ in a DSU system for confocality, which allowed the location of bacterial cells relative to the spermatozoids to be identified.

The detected intracellularity of $U$. diversum did not determine the integration of ureaplasma with spermatozoa DNA as questioned by Bielanski et al. [19]. However, Reichart et al. [16] concluded that $U$. urealyticum has a direct deleterious effect on the DNA and nuclear chromatin of human and ram spermatozoid. According to Cunha et al. [20], $U$. urealyticum resulted in clastogenic effects on human chromosomes and on the mitotic process itself, and the clastogenic effects varied with the $U$. urealyticum serotypes evaluated.

The invasion and survival of $U$. diversum inside bull spermatozoids were confirmed and measured by gentamicin assay as described by Yavlovich et al. [21]. The low-passage isolate (TOURO1) recovered from bull semen showed to be more invasive than the high-passage strain 49782, also recovered from bull semen. In fact, Thomas et al. [22] reported that the number of passages in vitro of $M$. bovis resulted in different invasion rates in cell cultures. The average rate of invasion of TOURO1 in bovine sperm was significantly higher than the isolates from cows. This may indicate that $U$. diversum recovered from bull semen may present a higher ability to invade bovine spermatozoids than the isolates recovered from cows. The binding affinity to sulfogalactoglycerolipid in germ membranes may vary among isolates of $U$. diversum and may influence their pathogenicity as suggested by Knox et al. [9]. Variations in the affinity of Mollicute receptors may interfere with their attachment to the host cells and may justify the variation in the rate of invasion. These variations explain the significantly higher rate of invasion of isolate A203 compared with the other isolates recovered from the same anatomic site.

The observations of $U$. diversum adherence and internalization in bull spermatozoids at $30 \mathrm{~min}$ of infection and the pattern of invasion did not change for the entire studied period of $6 \mathrm{~h}$. Díaz-Garcia et al. [23] described the maximum adherence of $M$. hominis in human 
Table 2 Determination of $\mathrm{CCU} / \mathrm{mL}$ of $U$. diversum field isolates and ATCC strains for gentamicin invasion assay and relative frequencies of invasion.

\begin{tabular}{|c|c|c|c|}
\hline Strains and isolates of $U$. diversum & Inoculums of tests $(\mathrm{CCU} / \mathrm{mL})^{a}$ & Inoculums after gentamicin exposure $(\mathrm{CCU} / \mathrm{mL})^{a}$ & Frequency of invasion $(\%)^{b}$ \\
\hline ATCC 49782 & $55.00 \pm 0.49$ & $0.55 \pm 0.4929$ & $1.03 \pm 0.92$ \\
\hline ATCC 49783 & $550.00 \pm 492.95$ & 1.00 & 0.18 \\
\hline A203 & $5.50 \pm 0.15$ & 0.10 & 1.81 \\
\hline ALVA & 100.00 & 1.00 & 1.00 \\
\hline 94 & $550.00 \pm 492.95$ & 1.00 & 0.18 \\
\hline 3175 & 1000.00 & $5.50 \pm 4.92$ & $0.55 \pm 0.49$ \\
\hline TOURO 1 & 1.00 & 0.10 & 10 \\
\hline
\end{tabular}

\footnotetext{
${ }^{a}$ Values $\mathrm{CCU} / \mathrm{mLx} 10^{4}$ of 3 independents tests performed in triplicate and standard deviations.
}

${ }^{b}$ Percentage of ureaplasmas presenting change of colors in broth $(\mathrm{CCU} / \mathrm{mL})$ after gentamicin exposure compared to initial inoculums $\mathrm{CCU} / \mathrm{mL}$ of test and standard deviations. 
sperm after 10 min post-infection probably due to the rapid saturation of membrane receptors of the spermatozoa by excessive toxic metabolic compounds released by mollicutes [24]. The ammonia released from ureaplamas may explain in part the results obtained throughout the studied infection.

The findings in the present study warn of a need for additional care to control the quality of bull semen for reproductive techniques [25]. The regular decontamination of semen was not sufficient to eliminate microorganisms such as $M$. bovis, M. bovigenitalium [19] and $M$. pulmonis [26] even when antibiotics were added. Knox et al [9], detected that the standard procedures for fertilization in humans did not always remove $M$. hominis from spermatozoa. Therefore, the intracellular location of mollicutes explains the failure of antibiotics to control these bacteria.

The association of gentamycin, tylosin and lincospectin is more effective than other antibiotics in inhibiting many opportunistic microorganisms including Mollicutes in bovine semen [6,27]. The Brazilian Ministry of Agriculture, Livestock, and Food Supply [28] requires the use of gentamycin $(250 \mu \mathrm{g})$, tylosin $(50 \mu \mathrm{g})$, lincomycin-spectinomycin $(150 / 300 \mu \mathrm{g})$ or penicillin (500 UI), streptomycin (500 UI) in semen. However, Marques et al. [29] isolated $U$. diversum in $37.14 \%$ of frozen bovine semen straws from Artificial Insemination Centers in Brazil that supply antibiotic dosages complying with national hygienic guidelines [28].

\section{Conclusions}

The infection in vitro of bovine spermatozoids with $U$. diversum provides conclusive evidence of the ability of this mollicute to enter and survive inside reproductive bovine cells making the control of these bacteria more difficult. The intracellular nature of bovine ureaplasma identifies a new difficulty to control the reproductive of these animals.

\section{Methods}

Strains and isolates of $U$. diversum and culture conditions $U$. diversum ATCC 49782 and 49783, and three isolates from vaginal mucus (ALVA, 3175, A203) and one isolate from bull semen (TOURO1) were studied. The microorganisms were previously stored at $-70^{\circ} \mathrm{C}$ and then cultured at $37^{\circ} \mathrm{C}$ in aerobic atmosphere in Ureaplasma Broth Medium supplemented with $\mathrm{CRML}^{\circledR}$ [30]. The ureaplasmal growth was expanded from $2 \mathrm{~mL}$ to $150 \mathrm{~mL}$ of broth, and confirmed by the alkaline shift and production of small dark brown colonies in solid medium [30].

\section{Labelling $U$. diversum cells}

The ureaplasmal growth was harvested from broth cultures by centrifugation at $15,000 x \mathrm{~g}$ for $50 \mathrm{~min}$ at $4^{\circ} \mathrm{C}$. The cell pellets were homogenized in $900 \mu$ l of fresh broth and mixed with $100 \mu$ l of 1:50 DilC $_{18}$ solution (Vybrant $^{\mathrm{TM}}$ Dil cell-labeling, solution-Dil, V-22885, Molecular Probe, Eugene, Oregon, USA) and incubated at $37^{\circ} \mathrm{C}$ for $50 \mathrm{~min}$. These suspensions were centrifuged at 20,600xg for $40 \mathrm{~min}$ at $4^{\circ} \mathrm{C}$ and washed in $1 \mathrm{~mL}$ PBS $2 \times(\mathrm{pH}$ 6.5). The fluorochrome labeled ureaplasma were centrifuged again in the same conditions and homogenized in $1.3 \mathrm{~mL} \mathrm{Sp-TALP} \mathrm{[31].}$

\section{Suspension of motile spermatozoids}

Ejaculates from three healthy bulls were pooled and diluted with Bovimix (Nutricell ${ }^{\circledR}$ Nutrientes Celulares, São Paulo, Brazil) without antibiotics and frozen at $-80{ }^{\circ} \mathrm{C}$ in aliquots of $250 \mu \mathrm{l}$. The semen was previously tested for mollicute contamination by PCR [32]. The frozen-thawed semen was layered in microtubes with a Percoll gradient (1:1 [vol/vol] mixture of $90 \% / 45 \%)$ and centrifuged at $9,000 x g$ for $5 \mathrm{~min}$ [33]. The spermatozoid sediments with actively motile cells were washed in $1 \mathrm{~mL}$ Sp-TALP by centrifugation at 6,000xg for $2 \mathrm{~min}$, homogenized in SpTALP and diluted to $10^{6}$ spermatozoids $/ 100 \mu \mathrm{l}$ Sp-TALP and evaluated for motility/vigor.

\section{Infection of spermatozoids with $U$. diversum}

The experimental infection of spermatozoids was performed as described by Díaz-Garcia et al. [12], with modifications. In microtubes, $100 \mu \mathrm{l}$ of $\mathrm{DiIC}_{18}$-labelled $U$. diversum cells were added to $100 \mu$ l of a spermatozoid suspension in microtubes. The ureaplasmal infected spermatozoids and the control of non infected spermatozoid suspensions were incubated at $37^{\circ} \mathrm{C}$ in $5 \% \mathrm{CO}_{2}$ for $30 \mathrm{~min}, 3$ and $6 \mathrm{~h}$. These tests were performed in duplicate for each time of incubation. The infective dose multiplicity was determined as described by Taylor-Robinson [34]. An aliquot of bacterial suspension was 10 -fold diluted in Ureaplasma broth for determination of $\mathrm{CCU} / \mathrm{mL}$. The viability of bacteria at different periods of incubation was confirmed on agar plates. Aliquots of infected and non infected spermatozoid suspensions were taken at different time-intervals for analysis of sperm motility/vigor. The motility was determined subjectively in percentage (\%) and the vigor on a scale of 0 to 5 , by microscopy $(400 \times)$. For confocal microscopy the spermatozoid cells were initially fixed with paraformaldehyde $3.7 \%$ for $20 \mathrm{~min}$ at room temperature, washed twice in PBS by centrifugation $(6,000$ $\times g$ for $2 \mathrm{~min}$ ) and homogenized in $100 \mu \mathrm{l}$ of PBS and stored at $4^{\circ} \mathrm{C}$.

\section{Confocal Microscopy}

Internalization of $U$. diversum into bovine spermatozoids was distinguished by fluorescence differences of fluorochromes exposed to the light filters of a confocal microscope. One-hundred fixed spermatozoid suspensions were centrifuged onto glass slides $(76 \times 26 \mathrm{~mm} / 3$ 
$\times 1$ inch) by a cytological centrifuge. The smears were permeabilized with Triton X-100 $0.5 \%$ for $10 \mathrm{~min}$,

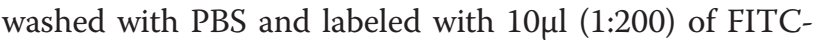
phalloidin $\left(\operatorname{Sigma}{ }^{\circledR}\right)$ for $40 \mathrm{~min}$ at room temperature. Next, the smears were washed twice in PBS, air-dried and mounted with a $24 \times 50 \mathrm{~mm}$ coverslip and Vectashield mounting fluid (Vector Laboratories, Burlingame, CA, USA). The slides with infected and non infected spermatozoids were observed by a Motorized Inverted System Microscope IX81 Olympus ${ }^{\circledR}$ ), coupled with an MT20 illumination system and a $60 \times$ oil immersion objective. The plane $\mathrm{Z}$-axis control was determined at $0.5 \mu \mathrm{m}$.

\section{Gentamicin invasion assay}

Labeled infected and non infected paired spermatozoid suspensions were incubated at $37^{\circ} \mathrm{C}$ with $5 \% \mathrm{CO} 2$ for 3 h. Next, these suspensions were washed in PBS and centrifuged at $6,000 x \mathrm{~g}$ for $2 \mathrm{~min}$. The obtained pellet of spermatozoids was homogenized with $200 \mu \mathrm{l}$ Sp-TALP with $400 \mu \mathrm{g} / \mathrm{ml}$ gentamicin and incubated for $3 \mathrm{~h} \mathrm{[21].}$ The antibiotic exposed suspension was centrifuged and spermatozoid sediment was homogenized with $200 \mu$ l of Ureaplasma medium and 10-fold diluted with the same broth, in triplicate, for determination of CCU/mL [34]. Each gentamicin resistance assay was repeated three times. Invasion frequencies were calculated as the difference of $\mathrm{CCU} / \mathrm{mL}$ of ureaplasma suspension samples before and after gentamicin exposure. The differences were calculated by Student's $t$ test. Differences with $P=$ 0.05 were considered significant.

\section{Acknowledgements \\ This study was supported by FAPESP (grant 06/56855-0). We thank Aricelma $P$. França for invaluable technical assistance and AcademicEnglishSolutions. com for revising the English.}

\section{Authors' contributions}

MB and JT: all tests realized in this study. BAC and GMMS: confocal analysis. MY, RCO, LMM: bacteria isolation and infection experiment. MEOA: motile spermatozoids acquisition. All authors read and approved the final manuscript.

\section{Competing interests}

The authors declare that they have no competing interests.

Received: 18 May 2011 Accepted: 27 October 2011

Published: 27 October 2011

\section{References}

1. Rae DO, Chenoweth PJ, Brown MB: Ureplasma infection in bovine. Archives of STD/HIV Research 1995, 7:239-243

2. Kreplin CM, Ruhnke HL, Miller RB, Doig PA: The effect of intrauterine inoculation with Ureaplasma diversum on bovine fertility. Can J Vet Res 1987, 51:440-443.

3. Howard CJ, Gourlay RN, Brownlie J: The virulence of T-mycoplasmas isolated from various animal species, assayed by intramammary inoculation in cattle. J Hyg Camb 1973, 71:163-170.
4. Fish NA, Rosendal S, Richard BM: The Distribution of Mycoplasmas and Ureaplasmas in the Genital Tract of Normal Artificial Insemination Bulls. Can Vet J 1985, 26:13-15.

5. Doig PA: Bovine genital mycoplasmosis. Can Vet J 1981, 22:339-343.

6. Guerin B, Thibier M: Value of adding antibiotics to frozen bovine semen: the example of Mycoplasmas and campylobacters. Contracept Fertil Sex 1993, 21:753-759.

7. Rosengarten R, Citti C, Glew M, Lischewski A, Droesse M, Much P, Winner F, Brank M, Spergser J: Host-pathogen interactions in mycoplasma pathogenesis: virulence and survival strategies of minimalist prokaryotes. Int J Med Microbiol 2000, 290:15-25.

8. Baseman JB, Lange M, Criscimagna NL, Giron JA, Thomas CA: Interplay between mycoplasmas and host target cells. Microb Pathog 1995, 19:105-116.

9. Knox CL, Allan JA, Allan JM, Edirisinghe WR, Stenzel D, Lawrence FA, Purdie DM, Timms P: Ureaplasma parvum and Ureaplasma urealyticum are detected in semen after washing before assisted reproductive technology procedures. Fertil Steril 2003, 80:921-929.

10. Saacke RG, Dalton JC, Nadir S, Nebel RL, Bame JH: Relationship of seminal traits and insemination time to fertilization rate and embryo quality. Anim Reprod Sci 2000, 60-61:663-677.

11. Winner F, Rosengarten R, Citti C: Vitro Cell Invasion of Mycoplasma gallisepticum. Infect Immun 2000, 44:4238-4244.

12. Díaz-Garcia FJ, Herrera-Mendoza AP, Giono-Cerezo S, Guerra-Infante FM: Mycoplasma hominis attaches to and locates intracellularly in human spermatozoa. Human Reproduction 2006, 21:1591-1598.

13. Ueno MM, Timenetsky J, Centonze V, Wewer JJ, Cagle M, Stein MA Krishnan M, Baseman JB: Interaction of Mycoplasma genitalium with host cells: evidence for nuclear localization. Microbiology 2008, 154:3033-3041.

14. Zúccari CESN, Carrijo PR, Leite PA, Scaldelai PRR, Rodovalho NCM, Zanenga CA, Kiefer C, Silva EVC: Selection bovine frozen semen in Percoll $^{\oplus}$ gradient on spermatic parameters. Rev Bras Saúde Prod An 2008, 9:3658-3668

15. Talkington DF, Davis JK, Canupp KC, Garrett BK, Waites KB, Huster GA Cassell GH: The effects of three serotypes of Ureaplasma urealyticum on spermatozoal motility and penetration in vitro. Fertil Steril 1991, 55:170-176.

16. Reichart M, Kahane I, Bartoo B: Vivo and In Vitro Impairment of Human and Ram Sperm Nuclear Chromatin Integrity by Sexually Transmitted Ureaplasma urealyticum. Infect Biol Reprod 2000, 63:1041-1048.

17. Núnez-Calonge R, Caballero P, Redondo C, Baquero F, Martinez-Ferrer M, Meseguer MA: Ureaplasma urealyticum reduces motility and induces membrane alterations in human spermatozoa. Human Reprod 1998, 13:2756-2761.

18. Sylla L, Stradaioli G, Manuali E, Rota A, Zelli R, Vincenti L, Monaci M: The effect of Mycoplasma mycoides ssp. Mycoides LC of bovine origin on in vitro fertilizing ability of bull spermatozoa and embryo development. Anim Reprod Sci 2005, 85:81-93.

19. Bielanski A, Devenish J, Phipps-Todd B: Effect of Mycoplasma bovis and Mycoplasma bovigenitalium in semen on fertilization and association with in vitro produced morula and blastocyst stage embryos. Theriogenology 1999, 53:1213-1223.

20. Cunha RA, Koiffman CP, Souza DH, Takei K: Clastogenic effects of different Ureaplasma urealyticum serovars on human chromosomes. Braz J Med Biol Res 1997, 30:749-757.

21. Yavlovich A, Tarshis M, Rottem S: Internalization and intracellular survival of Mycoplasma pneumoniae by non-phagocytic cells. FEMS Microbiol Lett 2004, 233:241-246.

22. Thomas A, Sachse K, Dizier I, Grajetzki C, Farnir F, Mainil JG, Linden A: Adherence to various host cell lines of Mycoplasma bovis strains differing in pathogenic and cultural features. Vet Microbiol 2003, 91:101-113.

23. Svenstrup FH, Fedder J, Abraham-Peskir J, Birkelund S, Christiansen G: Mycoplasma genitalium attaches to human spermatozoa. Human Reprod 2003, 18:2103-2109.

24. Rottem S, Naot Y: Subversion and exploitation of host by mycoplasmas. Trends Microbiol 1998, 6:436-440.

25. Bielanski A: Disinfection procedures for controlling microorganisms in the semen and embryos of humans and farm animals. Theriogenology 2007, 68:1-22. 
26. Fraser L, Taylor-Robinson D: The effect of Mycoplasma pulmonis on fertilization and preimplantation development in vitro of mouse eggs. Fertil Steril 1977, 28:488-498.

27. Shin SJ, Lein DH, Patten VH, Ruhnke $H L$ : A new antibiotic combination for frozen bovine semen 1. Control of mycoplasmas, ureaplasmas, Campylobacter fetus subsp. venerealis and Haemophilus somnus. Theriogenology 1988, 29:577-591.

28. Brasil: Normative Instruction 48 from the Brazilian Ministry of Agriculture, Livestock, and Food Supply: Portaria n ${ }^{\circ}$ 46, de 30 de julho de 2003. Diário Oficial da União 2003, 149:4-5.

29. Marques LM, Buzinhani $M$, Neto RL, Oliveira RC, Yamaguti $M$, Guimarães AMS, Timenetsky J: Ureaplasma diversum detection in bovine semen straws for artificial insemination. Vet Rec 2009, 165:572-573.

30. Ruhnke HL, Rosendal S: Useful protocols for diagnosis of animal mycoplasmas. In Mycoplasmosis in Animals: Laboratory Diagnosis. Edited by: Whitford HW, Rosenbusch RF, Lauerman LH. lowa, lowa State University Press; 1994:141-144.

31. Parrish JJ, Susko-Parrish J, Winer MA, First NL: Capacitation of Bovine Sperm by Heparin. Biol Reproduction 1988, 38:1171-1180.

32. Buzinhani M, Buim MR, Yamaguti M, Oliveira RC, Mettifogo E, Timenetsky J: Genotyping of Ureaplasma diversum isolates using Pulsed-Field Electrophoresis. Vet J 2006, 177:688-690.

33. Machado GM, Carvalho JO, Siqueira Filho E, Caixeta ES, Franco MM, Rumpf R, Dode MAN: Effect of Percoll volume, duration and force of centrifugation, on in vitro production and sex ratio of bovine embryos. Theriogenology 2009, 71:1289-1297.

34. Taylor-Robinson D: The role of mycoplasmas in non-gonococcal urethritis: a review. Yale J Biol Med 1983, 56:537-543.

doi:10.1186/1756-0500-4-455

Cite this article as: Buzinhani et al:: Invasion of Ureaplasma diversum in bovine spermatozoids. BMC Research Notes 2011 4:455.

\section{Submit your next manuscript to BioMed Central} and take full advantage of:

- Convenient online submission

- Thorough peer review

- No space constraints or color figure charges

- Immediate publication on acceptance

- Inclusion in PubMed, CAS, Scopus and Google Scholar

- Research which is freely available for redistribution

Submit your manuscript at www.biomedcentral.com/submit
C Biomed Central 